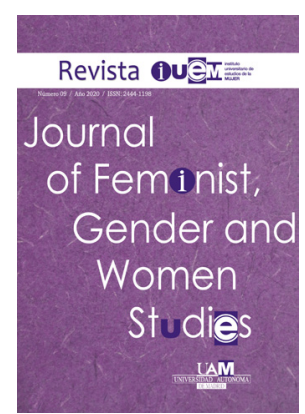

\section{El mito de Perséfone y el conflicto de la maternidad en Mother love, de Rita Dove}

\section{The myth of Persephone and the conflict of motherhood in Rita Dove's Mother love}

\author{
Cristina Salcedo González ${ }^{1, @ ~}$ \\ ${ }^{1}$ Universidad Autónoma de Madrid. \\ @ Autor/a de correspondencia: cristina.salcedog@uam.es
}

Recibido: $17 / 02 / 2020$

Aceptado: 21/04/2020

\title{
Resumen
}

Este artículo se propone estudiar de qué manera la modernidad introduce nuevas formas de interpretar el vínculo mítico entre Perséfone y Deméter. Para lograr este objetivo, se partirá, en primer lugar, de un estudio de las versiones clásicas de dicha relación y, en segundo lugar, de algunas interpretaciones influyentes ofrecidas en la modernidad. En tercer lugar, se analizará en detalle el acercamiento particular al vínculo madre-hija que propone Rita Dove en su poemario Mother Love (1995) y se desentrañarán las estrategias que esta escritora utiliza para alejarse de la visión idealizada del vínculo y así invocar una manera más compleja y rica de entender las identidades femeninas y, también, los vínculos entre mujeres.

Palabras clave: Mito clásico; Perséfone y Deméter; vínculos femeninos; maternidad; conflicto.

\begin{abstract}
This article aims to pin down the extent to which modernity introduces new ways of understanding and representing the mythical bond between Persephone and Demeter. In order to achieve this, I will first provide a critical review of the manner in which classical authors have interpreted the mother-daughter relationship; and, secondly, I will briefly refer to the most influential contemporary treatments of the bond. Thirdly, I will discuss the vision Rita Dove develops in her collection of poems Mother Love (1995) as well as the strategies she uses to depart from the idealised vision of the bond. This analysis will bring attention to Dove's particular understanding of the Persephone-Demeter relationship, one which detaches from the general tendency.
\end{abstract}

Keywords: Classical myth; Persephone and Demeter; female bonds; motherhood; conflict. 


\section{INTRODUCCIÓN}

El mito de Perséfone (lat. Proserpina) es uno de los más antiguos de la mitología griega, y su historia personifica temas universales, tales como la vida, la muerte y la resurrección. En su juventud, Perséfone mantiene una estrecha relación con su madre Deméter (lat. Ceres), diosa de las cosechas y del grano, y con todos los elementos naturales que esta última encarna; pero una vez que ha sido abducida por Hades (lat. Pluto), tío paterno de Perséfone y dios de los muertos, se convierte en la reina del inframundo $y$, junto a su marido, imparte justicia divina sobre los difuntos. Ya en la Antigüedad, el mito posee un doble valor: por un lado, el rapto de Perséfone se asocia en el arte helénico con la experiencia de la novia griega, quien deja atrás su vida anterior, su yo juvenil, para convertirse en esposa, mujer adulta, y empezar una nueva vida (Foley, 1994: 81). Pero el mito también se interpreta como parte de una alegoría del ciclo anual de la tierra, que permanece estéril durante los meses en los que Perséfone vive en el inframundo como consorte de Hades, y que florece cada primavera con su retorno a los brazos de Deméter. Es precisamente la naturaleza dual de Perséfone (deidad de la primavera y reina de los muertos; hija y esposa; inocencia y sabiduría) lo que la convierte en una figura tan poderosa y simbólica.

Pese a que la historia de esta diosa encarna numerosos temas, hay uno que, ya en la Antigüedad, recibe una atención especial: el vínculo poderoso que une a Perséfone y a Deméter, y la tragedia que entraña la ruptura obligada de dicho vínculo. Pero este interés no es exclusivo del mundo antiguo y, de hecho, la recepción de Perséfone en la literatura angloamericana del siglo $X X$ se encuentra estrechamente ligada al desarrollo y ampliación de este tema en concreto.

El objetivo de este artículo consiste en poner de manifiesto qué aporta la modernidad con respecto a la manera de concebir el vínculo entre Perséfone y Deméter. Para la consecución de este objetivo, ofreceré, en primer lugar, una revisión de las versiones clásicas de dicha relación, así como de algunas recreaciones contemporáneas. Esta revisión irá seguida del estudio pormenorizado del poemario Mother Love (1995, Rita Dove), una proyección moderna que explora una faceta de la relación a la que no se saca rendimiento en los textos clásicos y tampoco en las versiones posteriores del mito (al menos, en las más influyentes). Me estoy refiriendo, en particular, a la tensión, la hostilidad y la falta de entendimiento que puede llegar a caracterizar la relación entre una madre y su hija. Este análisis llamará la atención sobre las estrategias que Dove utiliza para alejarse de la visión idealizada del vínculo y así reivindicar, por medio de su tratamiento particular del mito, una manera más compleja y rica de entender las identidades femeninas y los vínculos entre mujeres. En último término, el presente artículo busca ser una aportación relevante con respecto a los estudios previos sobre el mito de Perséfone y la obra de Dove, que aquí se abordarán desde un punto de vista comparatista.

\section{PERSÉFONE: VERSIONES CLÁSICAS DE LA RELACIÓN} MADRE-HIJA

En las versiones antiguas del mito, se observan dos tendencias diferenciadas en la manera de representar el vínculo madre-hija. Un grupo considerable de autores no confiere importancia a la relación y ofrece una representación de Perséfone centrada en el gran poder que esta ejerce como consorte de Hades en el inframundo, así como en su vinculación con los procesos de la muerte. Alejada de su conexión con la abundancia, la vegetación y su madre, Perséfone se erige como reina poderosa y temible de los infiernos. En Homero (Od. XI. 634), por ejemplo, Perséfone, junto con su esposo Hades, tiene el control absoluto sobre los muertos; algunos de los adjetivos que el poeta utiliza para referirse a la diosa son terrible, ínclita, casta e ilustre (Hom. Od. X. 494, XI. 226, 385, 634). En las dos ocasiones en que se menciona a la diosa en la llíada (c. 750-725 a. C.), esta es descrita mediante la expresión "la atroz Perséfone" (II. IX. 457, 569). Complacida con su nuevo papel como esposa de Hades y reina de los infiernos, esta figura se halla muy distanciada - tanto física como emocionalmente- de su vida anterior en la tierra y no muestra ningún deseo de volver a los brazos de su madre. La diosa recibe un tratamiento similar en la Teogonía (c. 700 a. C.), donde "la terrible Perséfone" se encuentra siempre al lado del "robusto Hades" (Th. 768771). La Perséfone de Hesíodo desempeña con naturalidad la tarea de reinar sobre los muertos y se ha convertido en parte fundamental del paisaje infernal (Th. 768-771). En el mundo romano, destaca en este mismo sentido la caracterización de la diosa que ofrece Virgilio en su Eneida (c. 20 a. C.). En el momento en que Dido se suicida con la espada de Eneas, esta es incapaz de liberar el alma de su cuerpo, "Pues, dado que ni por su hado ni por muerte merecida perecía / [...] / No había aún Proserpina quitado de su cabeza el rubio / Mechón ni había aún adjudicado su persona al Orco estigio" (Aen. IV. 696-699. Trad. Rivero García et al., 2011). Como ocurría en Homero y Hesíodo, Perséfone - "Juno infernal" (Aen. VI. 138) - ha asumido el control absoluto de los procesos de la muerte y, en consecuencia, es ella quien ejerce el poder de determinar quién muere y cuándo.

Pero también hay un nutrido número de autores clásicos que convierte la relación madre e hija en la metáfora dominante del relato y que ensalza la conexión poderosa e idílica que comparten Perséfone y Deméter, al tiempo que subraya la faceta de Perséfone como diosa amable y benevolente de la primavera y de los ciclos de la naturaleza. En el Himno homérico a Deméter (c. 640 a. C.), algunas cuestiones léxicas apuntan a que esta Perséfone es diferente de la que se invoca en Homero: el título que se le asigna es el de "la muchacha de rostro sonrosado" (Him. Dem. 8, 27. Trad. José B. Torres Guerra, 2001); los atributos que se le adjudican son la luminosidad ("la de dorada espalda", 2), la bondad ("la hija de Deméter, santísima", 439), la belleza ("su hija de hermoso rostro", 333; "tu hija hermosísima", 493) y la prudencia ("la prudente Perséfone", 370). En el mundo idílico y pastoral deDeméter, Coré cultiva una relación íntima con su madre y los ciclos de la naturaleza (Him. Dem. 4-6); pero Hades perturba esa armonía al "raptarla de mal agrado en su carro de oro" (Him. Dem. 19). Tras esta experiencia infernal, la joven comienza a sucumbir, pues los recuerdos de su madre la atormentan sin cesar, y un dolor agudo se apodera de ella (Him. Dem. 430-435). En el Himno, Coré es víctima de la violencia masculina, que Deméter combate y trata de revertir, forzando, finalmente, el regreso (condicionado) 
de su hija. El reencuentro entre las dos diosas al final del Himno refuerza la idea de que la relación más importante de Perséfone es la que mantiene con su madre: "Perséfone, de la otra parte, [cuando vio los hermosos ojos] / de su madre, [...] / se lanzó a correr, [y a su cuello cayó abrazándola;]" (Him. Dem. 387-389). Esta Perséfone prefiere la vida en el mundo de los vivos junto a Deméter; madre e hija (frente a esposa y marido) forman un par indisoluble. El poeta lírico griego Baquílides (c. 520-450 a. C.) sigue la estela del Himno a Deméter en lo que se refiere a la representación de la diosa como Coré o muchacha (B. Fr. V. 296-297). Además, Baquílides subraya la conexión de Coré con los elementos naturales e introduce a la diosa en su faceta de hija y, por tanto, como pareja indisoluble de Deméter: "a la señora de Sicilia opima / Demetra, y su hija ornada de violetas" (B. Fr. III. 1-2). Y lo propio hace el mitógrafo griego Apolodoro en su Biblioteca mitológica (c. 1-2 d. C.), en la que Perséfone no adopta activamente el papel de reina del inframundo, sino que, al ser raptada por Hades, permanece en el reino de los muertos contra su voluntad, añorando en todo momento el mundo de su madre. En Apolodoro (I. 5), al igual que en el Himno, se potencia la asociación de Perséfone con el mundo natural y sus ciclos.

En consonancia con el Himno, Ovidio (en sus dos versiones poéticas del mito en latín) pone el acento en el vínculo inquebrantable que existe entre madre e hija; y lo hace, primero, a través de la exposición del dolor de ambas a causa de la separación (Met. V. 395-400; Fast. IV. 460-480) y, segundo, mediante el relato exhaustivo de la búsqueda sin descanso de Deméter (Ov. Fast. IV. 480-531; Ov. Met. V. 439-450). En las Metamorfosis, la idea de la conexión profunda entre madre e hija aparece reforzada al final de la canción de Calíope cuando esta detalla el estado de ánimo de Proserpina al volver a ver a su madre: "Al punto cambia / la expresión de su alma y de su rostro, pues la frente / de la diosa que ha poco podía parecer triste incluso a Dis, / está ahora alegre, tal como el sol, que antes estaba cubierto / de nubes de lluvia, sale victorioso de entre los nubarrones" (Ov. Met. V. 567-571. Trad. Ramírez de Verger y Navarro Antolín, 2007). Ovidio representa el regreso de la hija como una liberación o un triunfo gratificante: la vuelta de Proserpina insufla esperanza en el mundo, al igual que lo hace el sol a su salida cada mañana.

A modo de recapitulación, para autores como Homero o Virgilio, la relación madre-hija, así como la vinculación de Perséfone con los ciclos de la vegetación, no constituyen elementos centrales del relato. Sí es esencial, en cambio, la nueva responsabilidad que Perséfone contrae como reina terrible de los muertos. No obstante, otros autores (como el poeta anónimo del Himno y Ovidio, entre otros) enaltecen el vínculo Deméter-Perséfone y convierten a las dos diosas en prototipos idealizados y embellecidos de madre e hija. En estas versiones, tan fuerte es el vínculo entre Deméter y Perséfone (madre e hija; las fuerzas de la naturaleza, de la vida) que nada puede aniquilarlo, ni siquiera la relación paralela entre Hades y Perséfone (marido y mujer; las fuerzas de la muerte). Se observa, en último término, que los autores clásicos tienden a elegir una u otra faceta de Perséfone, uno u otro tema relacionado con la diosa y el mito. Perséfone es, en las fuentes clásicas, hija o esposa, víctima o culpable, diosa de la naturaleza o de los muertos. Desde la óptica clásica,
Perséfone parece desdoblarse en dos diosas diferentes, con dos facetas y caracteres opuestos.

\section{PERSÉFONE: PROYECCIONES CONTEMPORÁNEAS DE LA RELACIÓN MADRE-HIJA}

\section{Proyecciones idealizadas del vínculo: Perséfone como víctima}

En Of Woman Born: Motherhood as Experience and Institution (1976), un ensayo seminal en los acercamientos teóricos al concepto de la maternidad, Adrienne Rich reivindica la necesidad de recuperar (y representar) la relación entre una madre y su hija, una relación que, aunque poderosa y fundamental para la religiosidad griega antigua, ha perdido reconocimiento y vitalidad en el mundo actual (Rich, 1976: 237-240) ${ }^{1}$; y que, en efecto, no goza del desarrollo literario que sí disfrutan otras relaciones, como la que se establece entre el padre y el hijo (cf. Hamlet). Con este propósito, Rich estudia la más antigua y conocida imagen de esa relación, la que ofrece el Himno homérico a Deméter, y llega a la conclusión de que el mito expresa "the essential female tragedy", que consiste en la separación obligada entre una madre y una hija a causa de la intrusión, más o menos violenta, del hombre (Rich, 1976: 237-240). El Himno registra, además, "the mother-daughter passion and rapture" (1976: 237-240), esto es, el amor desmedido que fluye entre madres e hijas; $y$, en particular, la pasión y el compromiso de Deméter, siendo esta "paradigma del duelo materno, pero también del poder inmenso de ese duelo, que puede convertirse en una fuerza peligrosa y temible" (Morales Ortiz, 2007: 36). Es la furia de Deméter, Rich explica, la que hace posible el milagro del regreso de Perséfone (1976: 240-243). Por ello, y siguiendo a la estudiosa, el mito (o al menos la versión que ofrece el Himno) proyecta una imagen soñada por las madres e hijas de toda época y generación:

"Each daughter, even in the millennia before Christ, must have longed for a mother whose love for her and whose power were so great as to undo rape and bring her back from death. And every mother must have longed for the power of Demeter, the efficacy of her anger, the reconciliation with her lost self' (Rich, 1976: 237-240).

Esta interpretación idealizada del vínculo maternofilial $-y$, sobre todo, del poder de la madre- es especialmente fértil en la literatura angloamericana, que también se hace eco de este interés por describir (y reivindicar) las particularidades del vínculo que une a madres y a hijas, y advierte en el relato de Perséfone y Deméter un vehículo ideal y paradigmático para ello (Louis, 2009: 133) ${ }^{2}$. La imagen de la

\footnotetext{
1 "The loss of the daughter to the mother, the mother to the daughter, is the essential female tragedy. [...] The separation of Demeter and Kore is an unwilling one; it is neither a question of the daughter's rebellion against the mother, nor the mother's rejection of the daughter" (Rich, 1976: 237240).

2 Para entender ese interés en la literatura angloamericana por los vínculos maternofiliales, es necesario aludir al contexto sociocultural e ideológico en que se inscriben todas esas proyecciones. En concreto, me estoy refiriendo a la corriente feminista radical, afianzada en la Segunda Ola feminista (entre 1967 y 1975). Partiendo del pensamiento teórico de Millet (1969) y Firestone (1970), esta corriente defiende la diferencia sexual, los vínculos entre mujeres y la exaltación del principio femenino y sus valores. Daly (1978) y Rich (1976) fueron dos renombradas
} 
madre invencible cuyo amor por su hija todo lo vence es la que proyecta Hilda Doolittle (H. D.) en el poema breve "Demeter" (1921), donde la madre, quien conoce su poder inmenso ("I am greatest and least", v. II. 18), hace un llamamiento para que cesen "the tales that speak / of the death of the mother" (vv. 5-7). En los últimos versos del poema, Deméter compara sus brazos robustos y maternales, que protegen a su querida hija, con las manos crueles e implacables de Hades (vv. 1012); y afirma, por último, que el amor que siente por su hija es más poderoso que la pasión lasciva de Hades: "Ah, strong were the arms that took / (Ah, evil the heart and graceless), / but the kiss was less passionate" (vv. 10-12). Harriet Zinnes ("Demeter to Persephone", 1967), Kate Ellis ("Matrilineal Descent", 1980) y Enid Dame ("Persephone", 1985) ofrecen proyecciones similares a las de H.D. y, por tanto, reivindican la fuerza -inigualable, invencible- del amor que alberga Deméter. Podría trazarse, de hecho, una línea genealógica desde H.D. hasta Zinnes, Ellis y Dame, que, al mismo tiempo, cabría ampliar hacia delante y hacia atrás. Ahora bien, el funcionamiento de esta cadena de recepciones afines no es meramente lineal, sino que configura una matriz en cuyo seno "interactúa toda una red de conexiones con distintos puntos de anclaje y cuya emergencia está motivada por un gran número de factores diversos (políticos, sexuales, religiosos, sociológicos, entre otros muchos" (Unceta Gómez, 2019: 34).

Un rasgo adicional que interesa señalar aquí es que en estas actualizaciones (literarias y ensayísticas) del mito, la voz poética sitúa el foco de atención en la experiencia de la madre, algo que ya ocurría en algunas versiones clásicas (cf. Himno, Ovidio). Deméter es el prototipo enaltecido de madre y encarna una idealización del amor materno: ella representa a la madre todopoderosa, bondadosa, protectora, sustentadora, que da crecimiento, fertilidad y alimento; y que, además, mantiene con su hija una relación idílica, pues en ella solo tiene cabida el amor y la comprensión. Por su parte, Perséfone desempeña un papel secundario, supeditado al de la madre, y su identidad se establece en tanto que reflejo de la identidad de Deméter. Común a todas estas proyecciones es, asimismo, la tendencia a subrayar la vulnerabilidad e inacción de la hija, su posición como víctima estática en el acontecer de los hechos. Ahora bien, existen otras formas de experimentar la maternidad y, por tanto, es posible encontrar otras lecturas de la relación mítica, así como de las figuras que la integran. A continuación, se estudiará la recreación de Rita Dove, que precisamente emplea el mito de Perséfone para ofrecer una visión alternativa - problemática y conflictivade la relación madre-hija.

\section{Una proyección conflictiva del vínculo: Perséfone como mujer compleja}

Mother Love (1995), de la escritora americana, ganadora del premio Pulitzer, Rita Dove, ilustra de manera paradigmática la tendencia a utilizar el mito de Perséfone

defensoras del feminismo radical en el contexto angloamericano; y de sus reivindicaciones se nutrieron un gran número de escritoras que trataron de plasmar literariamente todas esas inquietudes. Además, el feminismo radical tuvo una gran acogida en otras muchas sociedades y, por tanto, sus reivindicaciones están presentes en otras literaturas (véase, por ejemplo, Cixous, 1976). para reflexionar acerca de la ambivalencia, la tensión y la falta de entendimiento que puede recubrir el vínculo entre una madre y su hija. En Mother Love, y también en los volúmenes de poesía precedentes, Thomas and Beulah (1987) y Grace Notes (1989), Dove ahonda en el tema del conflicto y la familia desde perspectivas diferentes (la de una mujer y un marido, y la de una joven madre, respectivamente); estas tres obras constituyen, en palabras de Logfren (1996: 141), una trilogía de los ciclos de la existencia humana. Ahora bien, es interesante constatar que solo en Mother Love la mitología es un recurso de expresión productivo, lo que tiene que ver con la capacidad del relato de Perséfone en concreto para apelar a las madres y las hijas de hoy.

Mother Love consta de siete libros; cada uno formado por un grupo de sonetos, cuyos títulos aluden, de manera explícita o implícita, al mito de Perséfone. Complementarias entre sí, las historias y experiencias de las madres e hijas de Mother Love siguen la estructura esencial del Himno homérico a Deméter, pero Dove actualiza el sentido de los núcleos estructurales del relato clásico al trasladarlos a una gran variedad de contextos contemporáneos (p. ej. un bistró, un pub parisino, etc.) y a una gran variedad de subjetividades modernas (numerosas madres e hijas de la clase media americana). En el prólogo, titulado "An intact world", Dove adelanta la preocupación que guiará toda la secuencia poética: "The ancient story of Demeter and Persephone [...] is a modern dilemma [...]-there comes a point when a mother can no longer protect her child, when the daughter must go her own way into womanhood" (Dove, 1995). En efecto, Mother Love propone una reflexión sobre ese complicado momento de transición en el que la hija experimenta la urgencia de alejarse de su madre para forjarse un yo propio.

La primera alusión explícita al mito se produce en el título del soneto "Persephone, Falling" (Book II: págs. 5-29) donde, en la primera octava, la voz poética presenta a una Perséfone que arranca con vehemencia "one narcissus among the ordinary beautiful / flowers, one unlike all the others!" (vv. 1-2). Símbolo de la sexualidad y del inframundo, el narciso contiene la promesa de acceso a un nuevo conocimiento y a nuevas experiencias vitales. En el libro III (titulado "Persephone in Hell", págs. 23-33), que ahonda en este deseo irreprimible de Perséfone de arrancar el narciso, el lector descubre que la hija se ha ido a estudiar a París junto a un grupo de amigas. A través del mitema clásico del descenso al inframundo (catábasis) ${ }^{3}$, Dove explora los sentimientos contradictorios que afloran en la hija a raíz de su experiencia de un mundo que ella describe en términos de "instantly foreign" (v. 25): Perséfone cruza el umbral ("I stepped over the tinkling threshold", III. v. 24), y una suerte de desorientación vital la embarga (vv. 32-34). Esta sensación de extrañeza, de alienación y de no pertenencia que Dove expresa en términos de caída al infierno permea toda la experiencia de la hija: "French nothings. / I don't belong here" (VI. vv. 5-6). Ahora bien, la Perséfone de Dove también es consciente de que esta marcha le ha ofrecido una apertura al mundo ("Well, the world's open", V. v. 11) y, de hecho, está satisfecha de haberse alejado por un tiempo de "Mother with her frilly ideals" (III. v. 1); al fin y al cabo, la hija afirma, hay

3 "It was not quite twenty when she first went down / into the stone chasms of the City of Lights" (III. v. 1-2). 
vivencias y emociones que su madre no podría entender; que debe experimentar en solitario: "but she couldn't know what I was feeling; / I was doing what she didn't need to know. / I was doing everything and feeling nothing" (III. vv. 3-5). Perséfone reflexiona, también, sobre su iniciación sexual ("I don't believe I was suffering. I was curious, / mainly", vv. 25-26) y, mediante la metáfora de la flor, expresa su anhelo voraz de experimentar el placer carnal, de ahogarse en un mar de flores ("How would each one smell, how many ways could / he do it? / I was drowning in flowers", vv. 27-29). La Coré inocente y virginal del Himno y de las Metamorfosis, la que busca la flor más bonita para regalársela a su madre, se descarta en favor de un acercamiento contemporáneo a la sexualidad femenina.

En el libro IV (págs. 35-42), Dove profundiza en la vida de Perséfone en el París infernal e introduce a Hades, un hombre de cabeza grande "like a cynical parrot" y sonrisa oscura (IV. vv. 14, 15) que seduce a Perséfone en un lúgubre bar parisino. En "Hades' Pitch" (IV), la hija subraya que en esta historia no hay violación; que es ella quien ha decidido entregarse al deseo sexual (IV. v. 11). Son las palabras de Hades las que tienen el poder de atraparla y, por tanto, las que adoptan la función que el narciso desempeña en el mito clásico: "He was good / with words, words that went straight to the liver" (IV. vv. 6-7). En esta actualización, la iniciación (sexual, intelectual) de Perséfone no se produce por imposición masculina, sino que se representa como un proceso en el que ella decide sumergirse, como una transición necesaria y enriquecedora. Si bien esa experiencia se plantea como una iniciación necesaria, el hombre particular con quien esa iniciación se lleva a cabo resulta irrelevante: el Hades de Mother Love desaparece para siempre de la vida de Perséfone, por lo que pierde su valor simbólico como figura particular, al tiempo que la experiencia de la hija cobra protagonismo ${ }^{4}$.

En esta proyección mítica madre e hija se reencuentran en el mundo de la hija, a saber, en el inframundo parisino, lo que contrasta con la narración del Himno o las Metamorfosis, donde se reúnen en el mundo de la madre. En el poema del reencuentro ("The Bistro Styx"), Dove adopta la perspectiva de la madre, quien, al ver a su hija, se percata de que la oscuridad se ha impreso en "my blighted child" (IV. v. 14). La madre observa a Perséfone con ojos críticos y ofrece juicios incisivos sobre su aspecto y comportamiento: "[...] She did look ravishing, / spookily insubstantial, a lipstick ghost on tissue" (IV. vv. 49-50). La hostilidad y el crispamiento alcanzan su punto álgido en el momento en que la Deméter de Dove menciona aquello que, en su opinión, se ha interpuesto entre ambas:

\section{"How's business?" I asked, and hazarded a motherly smile to keep from crying out: Are you content to conduct your life as a cliché and, what's worse,}

\footnotetext{
4 Pese a que Dove pone el foco de atención en la experiencia de la hija, la respuesta psicológica de Deméter ante la pérdida de la hija también cobra importancia en la obra. En el poema "The Search", Dove imagina a una madre "blown apart by loss" (v. 1), que, como Deméter en el mito clásico, se olvida de sí misma y descuida su aspecto, "wandered the neighborhood [...], breasts / swinging under a ratty sweater, crusted / mascara blackening her gaze" (vv. 2-4). La escritora empatiza con el dolor de la madre y da voz a su duelo, que parece no tener fin: su pena es excesiva y, en este sentido, mítica.
}

an anachronism, the brooding artist's demimonde? (IV. vv. 15-19).

Esta Deméter desaprueba y cuestiona dos aspectos fundamentales en la vida de la hija: su carrera profesional (esfera pública) y su vida amorosa (esfera privada). Molesta por la intromisión de su madre, la Perséfone de Dove siente la necesidad de defender su estilo de vida, de expresar su bienestar y frustrar así las conjeturas de la madre: "Tourists love us. The Parisians [...] / [...] are amused, though not without / certain admiration...' / [...] / the aplomb with which we've managed / to support our Art' - meaning he'd convinced / her to pose nude for his appalling canvases" (vv. 26-28, 36-38). De nuevo, la madre, en paralelo, reinterpreta la información que la hija le está ofreciendo. El lector percibe a Perséfone a través de los ojos de la madre y, por medio de esta estrategia, Dove expone los prejuicios de esta última, así como el modo en que estos son un obstáculo en la relación madre-hija. En los últimos versos, Dove proyecta la imagen de una hija insaciable, que consume ávidamente el alimento del inframundo - "a black plug", "a bloody / Pinot Noir" (vv. 31, 34-45). La madre, que la observa con suspicacia y desesperanza al darse cuenta de que "Nothing seemed to fill / her up" (v. 61-62), le pregunta si es feliz en su nuevo hogar ( $v$. 67), a lo que la hija responde "'one really should try the fruit here'" (vv. 70). Esta respuesta es concluyente no solo para la madre, que en el poema sentencia "I've lost her" (v. 71), sino para el lector familiarizado con el mito y conocedor de la consecuencia que la ingesta de comida infernal tiene sobre Perséfone. El relato antiguo sirve ahora de clave interpretativa: la Perséfone de Dove ha probado la fruta infernal, símbolo de la sexualidad y también del conocimiento, y esto permite a la madre (y al lector) entender el alcance de la iniciación (y la consecuente distancia) de la hija.

A pesar de que Dove parece sugerir que el vínculo madre-hija cambia, sufre y se desgasta a consecuencia del desarrollo personal de la hija, la autora también apunta a la reconciliación y a un posible acercamiento. En "Missing" (Book VI: pág. 62), Dove presenta a una Perséfone que consigue entender el dolor obsesivo y disfuncional de la madre y empatizar con su pérdida: "I am the daughter who went out with the girls, / never checked back in and nothing marked my 'last / known whereabouts,' [...] / [...] A lost / child is a fact hardening around its absence" (vv. 1-3, 4-5). Por un lado, la hija se percata de que Deméter siempre va a formar parte de sí misma y de que, por tanto, es inmortal: "Now I understand she can never / die" (v. 11-12). Y también reconoce, por otro lado, que sus experiencias la han transformado por completo, al hacerla partícipe de dos mundos y de dos realidades diferentes: "nothing can bring me back - / I am the one who comes and goes; / I am the footfall that hovers" (vv. 12-14). La Perséfone de Dove es capaz de empatizar con la madre y, a la vez, de reivindicar la separación o distanciamiento de esta como parte necesaria del ritual de hacerse mayor.

En sentido contrario, el viaje de aprendizaje de la madre, la reconciliación con la hija y consigo misma, es más complicado y, tal y como Dove muestra en varios poemas ( $p$. ej. "Demeter, Waiting"), está marcado por falsos comienzos, decepciones, momentos de confusión y de soledad. Pero la Deméter de Dove logra acercarse a su hija y experimentar algo de tranquilidad cuando se da cuenta de que Perséfone 
está viviendo lo mismo que ella experimentó: "I've walked there, too" ("Afield", V. v. 9). La Deméter de Dove renuncia a su destino mítico, es decir, al llanto y a la amargura que condicionan para siempre la vida de la Deméter (y Perséfone) del Himno, para adoptar una actitud más tolerante, flexible y empática con respecto a su hija: "There are no curses [...] / And so I give up this fate, too" (V. vv. 11, 13). Una vez que abandona el papel de madre doliente, esta Deméter es capaz de enfrentarse a aquello que antes no podía imaginar, a saber, el hecho de que su hija desee marcharse y desarrollar una vida independiente de la suya; y desde una calma recién adquirida y aprendida, anima a Perséfone a emprender con valentía ese viaje: "Believe in yourself, go ahead-see where it gets you" (V. vv. 14-15). Dove dramatiza, entonces, un aprendizaje doloroso y necesario que incumbe a madres e hijas por igual y que, por lo tanto, es doble. Madre e hija consiguen establecer una relación más armoniosa a través del reconocimiento de los deseos y las necesidades de la otra. De manera acertada, Logfren (1996: 141) afirma que la reelaboración de Dove "demands a harmony based not on the passage of the seasons so much as on mutual respect for individual needs-the mother's, the daughter's, [...] a call for compassion and compromise". Mother Love es, en definitiva, un canto a uno de los gestos más generosos y complicados que madres e hijas pueden dedicarse en el transcurso de sus vidas: dejar marchar para dejar ser.

Pero esta escritora no es la única que se interesa por repensar y reimaginar la relación ambivalente entre madre e hija y que ve en el mito de Perséfone el vehículo apropiado para ello. Olga Broumas ("Demeter", 1977), Alicia Ostriker ("Demeter to Persephone", 1937) y Eavan Boland ("The Pomegranate", 1944) profundizan también en este tema, y lo hacen desde el punto de vista de la madre. Por su parte, Stevie Smith ("Persephone", 1968), Carolyn Kizer ("Persephone Pauses", 1984), Nan Fry ("From Persephone's Letters to Demeter", 1991) y Shara McCallum ("Persephone Sets the Record Straight", 1999) adoptan la perspectiva de la hija y representan el modo en que esta vive esos momentos de desencuentro con la madre. Se constata, entonces, que no existe una manera única de interpretar este vínculo complejo, sino múltiples formas de entenderlo y de representarlo; que hay numerosas formas de concebir a la madre y a la hija; y que estas son figuras plurales y maleables. En todos los casos se observa un interés compartido por el vínculo madre-hija y, sobre todo, por el modo en que dicho vínculo se manifiesta en la actualidad y consigue renovar su poder y carga simbólica.

\section{CONCLUSIONES}

A modo de recapitulación, se ha podido comprobar que algunos autores clásicos no confieren importancia a la relación madre-hija, sino que les interesa subrayar la faceta de Perséfone como diosa terrible del inframundo, su nueva relación con Hades y con los procesos de la muerte. Por el contrario, otros autores grecorromanos convierten la relación materno filial en la metáfora dominante del texto: en estas versiones, Perséfone es víctima del rapto y, aunque obligada a permanecer un tiempo en el inframundo, no llega a adoptar el papel de reina infernal de manera activa. Se hace hincapié, entonces, en la vinculación de Perséfone con su madre y, por extensión, con los ciclos de la naturaleza. En el siglo XX el texto de Rich marca el sentido de la recuperación del mito en el ámbito angloamericano, al tiempo que sienta las bases para los discursos sobre las maternidades que se gestan a lo largo del siglo XX. En el ámbito literario, mientras que algunas escritoras siguen la estela de la lectura idealizada del vínculo y presentan a Perséfone en su faceta de hija inocente y víctima del rapto, otras profundizan en la complejidad de la relación que une a madres e hijas y, entonces, exploran la posibilidad de que Perséfone haya decidido emprender una nueva vida, independiente de la de su madre, con el objetivo de alcanzar un yo propio. Tal es el caso de Mother Love, donde Perséfone emerge como una figura dinámica, compleja y ambivalente, que está inmersa en un proceso de transición y de transformación; que se encuentra a medio camino entre dos mundos y dos estados de ánimo; que se marcha y regresa; que deja de ser una cosa, para retomarla en un futuro; que, en definitiva, se sitúa en el umbral de la vida y de sus decisiones. Ella encarna a la hija rebelde que solo tiene en cuenta sus deseos y necesidades; pero también es la hija que sufre las consecuencias del comportamiento dependiente y sobreprotector de la madre y se siente incapaz de romper el vínculo materno; o la hija que, como mujer adulta, ha aprendido a ponerse en el lugar de la madre.

En la recreación de Dove, Perséfone ( $y$, también, Deméter) es una mujer compleja, inmersa en procesos vitales de cambio, en la que afloran contradicciones propias del ser humano; y, desde este punto de vista, es posible afirmar que la autora consigue trascender la visión reduccionista y maniquea en torno a la mujer que se desprende de textos tanto clásicos como modernos. Perséfone tiene la capacidad de ser reflejo del dinamismo, el potencial, la complejidad, la diversidad y la riqueza que albergan las identidades femeninas y los vínculos entre mujeres. Y es esta capacidad del mito de Perséfone para dar respuesta a las preocupaciones de las madres y las hijas de hoy la que favorece que este siga siendo hoy un vehículo de expresión relevante.

\section{REFERENCIAS}

Anónimo. 2001. Himno Homérico a Deméter. Trad. José B. Torres Guerra. Pamplona: Ediciones Universidad de Navarra.

Apolodoro. 2004. Biblioteca mitológica. Trad. Julia García Moreno. Madrid: Alianza editorial.

Baquílides. 1988. Odas y Fragmentos. Trad. Fernando García Romero. Madrid: Editorial Gredos.

Boland, Eavan. 1995. Collected Poems. Manchester: Carcanet. Broumas, Olga. 1977. Beginning With O. New Haven: Yale University Press.

Dame, Enid. 1985. Persephone. The New York Quarterly, 28: 60-63.

Dove, Rita. 1995. Mother Love. Nueva York: W. W. Norton \& Company.

Ellis, Kate. 1980. Matrilineal Descent. En Rod Tulloss, David Keller y Ostriker, Alicia (eds.) US 1: An Anthology, 31-34. Nueva Jersey: Wise.

Fry, Nan. 1991. Relearning the Dark. Washington: Washington Writers' Publishing House.

H.D. 1983. Collected Poems 1914-1944. Ed. Louis L. Martz. Nueva York: New Directions.

Hesíodo. 2000. Teogonía. Trabajos y Días. Escudo. Certamen. 
Trad. Adelaida Martín Sánchez, \& María Ángeles Martín Sánchez. Madrid: Alianza Editorial.

Homero. 2000. Odisea. Trad. José Luis Calvo. Madrid: Cátedra. Homero. 2010. Ilíada. Trad. Emilio Crespo Güemes. Madrid: Editorial Gredos.

Kizer, Carolyn. 1961. The Ungrateful Gardens. Bloomington: Indiana University Press.

McCallum, Shara. 1999. The Water Between Us. Pittsburgh: University of Pittsburgh Press.

Ostriker, Alicia. 2009. Demeter to Persephone. Ploughshares, 35(1): 120-121.

Ovidio. 1990. Fastos. Trad. Manuel Antonio Marcos Casquero. Salamanca: Universidad de León. Servicio de Publicaciones.

Ovidio. 2007. Metamorfosis. Trad. Antonio Ramírez de Verger y Fernando Navarro Antolín. Madrid: Alianza Editorial.

Smith, Stevie. 1975. The Collected Poems of Stevie Smith. Londres: Allen Lane.

Virgilio. 2011. Eneida. Trad. Luis Rivero García, Juan A. Estévez Sola, Miryam Librán Moreno, y Antonio Ramírez de Verger. Madrid: Consejo Superior de Investigaciones Científicas.

Zinnes, Harriet. 1967. Demeter to Persephone. Prairie Schooner, 41(1): 86-87.

\section{Estudios}

Cixous, Hélène. 1995 [1976]. La risa de la medusa: ensayos sobre la escritura. Barcelona: Anthropos.

Daly, Mary. 1978. Gyn/Ecology: The Metaethics of Radical Feminism. Boston: Beacon.

Dove, Rita. 1987. Thomas and Beulah: Poems. Pittsburgh: Carnegie-Mellon University Press.

Dove, Rita. 1991. Grace Notes: Poems. Nueva York: Norton.

Firestone, Shulamith. 2003. The Dialectic of Sex: The Case for Feminist Revolution. Farrar: Straus y Giroux.

Foley, Helene P. 1994. The Homeric Hymn to Demeter: Translation, Commentary, and Interpretive Essays. Princeton: Princeton University Press.

Harrison, Jane Ellen. 1961. Prolegomena to the Study of Greek Religion. Londres: Merlin.

Lofgren, Lotta. 1996. Partial Horror: Fragmentation and Healing in Rita Dove's "Mother Love". Callaloo, 19(1): 135-142.

Louis, Margot K. 2009. Persephone Rises, 1860-1927: Mythography, Gender, and the Creation of a New Spirituality. Burlington: Ashgate.

Millett, Kate. 2016. Sexual Politics. Nueva York: Columbia University Press.

Morales Ortiz, Alicia. 2007. La maternidad y las madres en la tragedia griega. En Antonio Calderón, Esteban y Morales Ortiz, Alicia (eds.) La madre en la Antigüedad: literatura, sociedad y religión, 129-167. Madrid: Signifer.

Rich, Adrienne. 1976. Of Woman Born: Motherhood as Experience and Institution. Nueva York: W. W. Norton and Company.

Unceta Gómez, Luis y Carlos Sánchez Pérez (eds.). 2019. En los márgenes de Roma. La Antigüedad romana en la cultura de masas contemporánea. Madrid: Catarata. 